\title{
INSPEÇÃO CADASTRAL E ROTINEIRA EM OBRAS DE ARTE ESPECIAIS NAS REGIÕES NORTE E NORDESTE DO BRASIL: ESTUDO DE CASO
}

\author{
PEREIRA, RODRIGO \\ Engenheiro Civil \\ Strata Engenharia Ltda. \\ Minas Gerais; Brasil \\ rodrigoestruturas@gmail.com \\ MARTINS, VITOR ARAÚJO \\ Engenheiro Civil \\ Strata Engenharia Ltda. \\ Minas Gerais; Brasil \\ vitoraraujomartins@outlook.com
}

\author{
DO CARMO, ANNE KAROLINE FORTUNATO \\ Engenheira Civil \\ Pontifícia Universidade Católica de Minas Gerais \\ Minas Gerais; Brasil \\ annekarolinefc@gmail.com
}

\author{
DE ALENCAR, CECÍLIA NARDI \\ Estudante \\ Universidade Federal de Minas Gerais \\ Minas Gerais; Brasil \\ cecilia.nardi@hotmail.com
}

\section{RESUMO}

As Obras de Arte Especiais (OAEs) são estruturas viárias que permitem o desenvolvimento urbano por meio de melhoria do tráfego de pessoas e cargas. No Brasil, a maior parte das pontes e viadutos são projetadass e executadas tendo o concreto como principal material de construção. Além da deterioração natural que o material sofre e da ausência de manutenção adequada, há ainda erros de concepção e execução, ou deficiências funcionais, que acabam por influenciar negativamente na vida útil das estruturas. Esses fatores geram danos, tecnicamente conhecidos como manifestações patológicas, que podem evoluir em termos de agressividade e dimensões, de forma a resultar em insuficiências estruturais. Dessa maneira, faz-se necessário que as obras recebam acompanhamento por meio de inspeções periódicas. O objetivo do presente trabalho foi, por meio de inspeções realizadas, identificar e avaliar as principais manifestações patológicas e deficiências funcionais de obras selecionadas nas Regiões Norte e Nordeste do Brasil, de forma a traçar estatísticas sobre as ocorrências.

Palavras-chave: manifestações patológicas, inspeção visual, estruturas de concreto, obras de arte especiais.

\section{ABSTRACT}

Bridges and viaducts are road structures that allow urban development by allowing the traffic of people and cargo. In Brazil, most bridges and viaducts are designed and built with concrete as their main building material. In addition to the natural deterioration of the material and the lack of proper maintenance, there are design and execution errors, or functional deficiencies, which negatively influence the service life of the structures. These factors generate damage, technically known as pathological manifestations, which may evolve in terms of aggressiveness and size, resulting in structural insufficiencies. Thus, it is necessary that the works receive monitoring through periodic inspections. The objective of this work was, through inspections, to identify and evaluate the main pathological manifestations and functional deficiencies of selected works in the North and Northeast of Brazil, in order to draw statistics on the occurrences.

Keywords: pathological manifestations, visual inspections, concrete structures, bridges.

\section{INTRODUÇÃO}

Sabe-se que o Brasil é um país com características geográficas e hidrográficas muito variadas. Além disso, é sabido que o modal rodoviário constitui-se como o principal modal do país, tanto para o transporte de pessoas como de cargas. A associação desses dois fatores com o crescimento das cidades e da intensificação das relações comerciais e interpessoais resulta na necessidade cada vez maior de construção de pontes e viadutos.

Inicialmente improvisadas por troncos de árvores e rochas, as obras de arte especiais sofreram evoluções nos seus processos construtivos, aproveitando-se do desenvolvimento de novos materiais de construção e desenvolvendo novos 
sistemas estruturais. No Brasil, a maior parte das OAEs foi construída tendo o concreto como o seu principal material de construção.

O pensamento de que as estruturas de concreto tinham vida útil infinita foi gradativamente desmentido, reconhecendose que um programa de manutenção e prevenção de suas patologias é indispensável para que as obras atendam ao tempo minímo a qual foram projetadas (BASTOS, MIRANDA, 2017).

Conforme o Manual 709, ou Manual de Inspeção de Pontes Rodoviárias do DNIT (2004), o concreto pode ter a sua degradação natural acelerada por diversas causas, prejudicando o seu desempenho e reduzindo a sua vida útil. Destacam-se as falhas de projeto e concepção, ausência de controle de qualidade na construção, manutenção inexistente ou inadequada, utilização inadequada da estrutura e exposição a sobrecargas superiores às de dimensionamento.

No caso dos erros de concepção e inconformidades do projeto com as normas vigentes, geram-se deficiências funcionais nas obras, ou em outras palavras, os elementos e características da OAE não atendem adequadamente às suas funções. Associado aos demais fatores citados, as deficiências contribuem com a deterioração do concreto, dando origem às manifestações patológicas.

\section{DESENVOLVIMENTO}

\subsection{Metodologia}

Foram selecionadas aleatoriamente 3 Obras de Arte Especiais, de cada um dos 11 estados representados na figura 1 (Alagoas, Bahia, Ceará, Maranhão, Pará, Paraíba, Pernambuco, Piauí, Rio Grande do Norte, Sergipe e Tocantins), que atendessem aos critérios pré-estabelecidos: as OAEs deveriam possuir características de obras construídas entre 1960 e 1975, conforme o Manual 709. Ou seja, deveriam possuir características de obras dimensionadas para o trem tipo TB36 e 10,0 m de largura. Além disso, determinou-se que as obras deveriam possuir entre 20,0 e 40,0 m de extensão, com excessão de Sergipe, onde por falta de obras, adotaram-se duas outras OAEs com extensões aproximadas à faixa de interesse. A lista das pontes e viadutos selecionados, assim como suas respectivas localizações, extensões, sistemas estruturais e número de vãos podem ser verificados na Tabela 1.

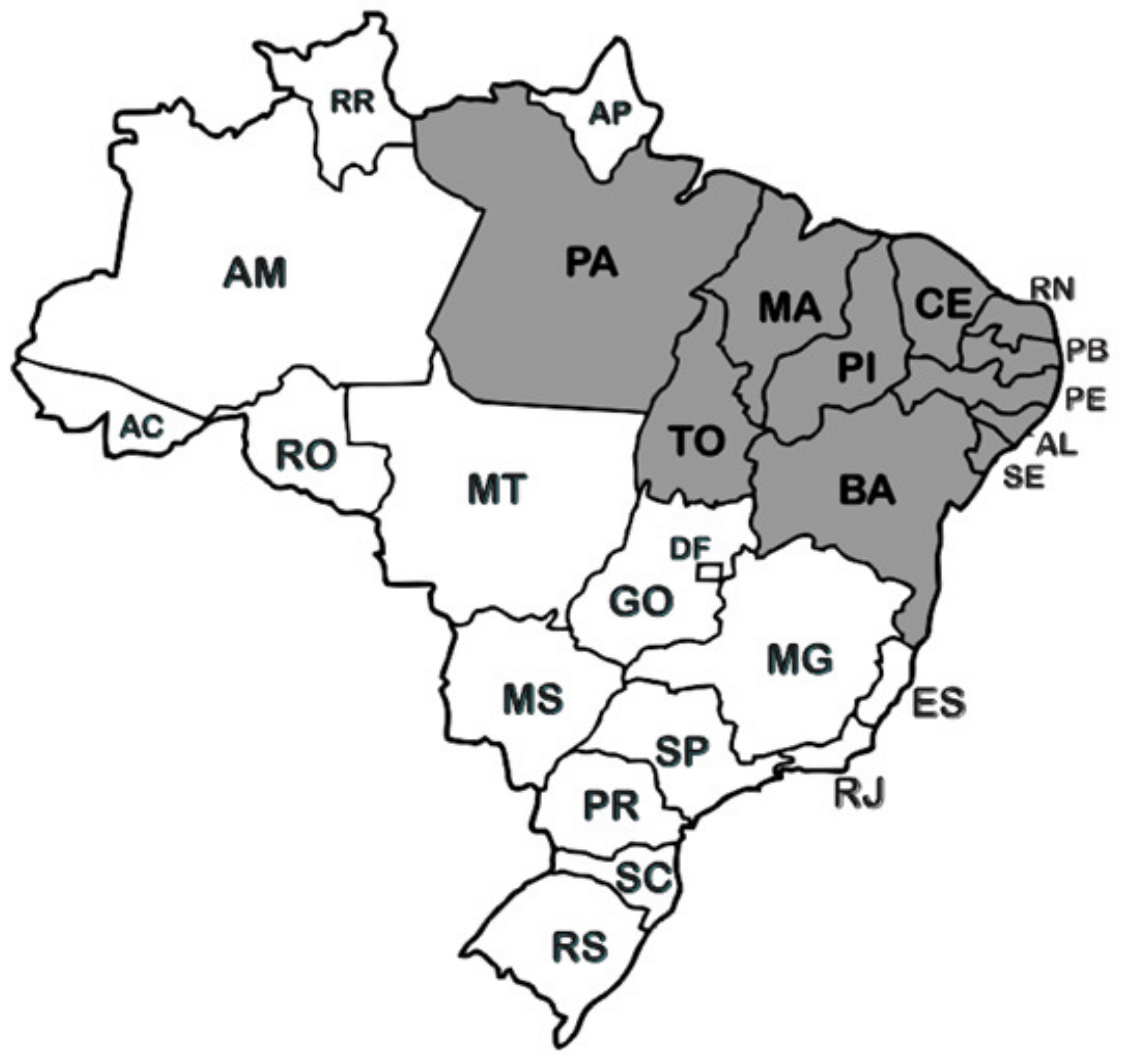

Figura 1: Mapa dos estados analisados (adaptado de Infoescola). 
Tabela 1 - OAEs selecionadas e suas principais características

\begin{tabular}{|c|c|c|c|c|c|c|c|}
\hline \multirow{2}{*}{ UF } & \multirow{2}{*}{ Rodovia } & \multirow{2}{*}{ Nome } & \multirow{2}{*}{ Extensão $(m)$} & \multicolumn{2}{|c|}{ Coordenadas } & \multirow{2}{*}{ Vãos } & \multirow{2}{*}{ Sistema estrutural } \\
\hline & & & & Latitude & Longitude & & \\
\hline \multirow{3}{*}{ AL } & BR-104 & Ponte sobre o Riacho Branca dos Tavares & 30,00 & $9^{\circ} 14.530^{\prime} \mathrm{S}$ & $36^{\circ} 0.685^{\prime} \mathrm{O}$ & 1 & Viga caixão de concreto armado \\
\hline & BR-104 & Ponte sobre o Rio Bulangi & 30,50 & $9^{\circ} 19.931 ' S$ & $35^{\circ} 53.952^{\prime} \mathrm{O}$ & 2 & Viga T ou I de concreto armado \\
\hline & BR-104 & Ponte sobre o Riacho Sueca & 20,50 & $9^{\circ} 8.158^{\prime} \mathrm{S}$ & $36^{\circ} 1.332^{\prime} \mathrm{O}$ & 1 & Viga T ou I de concreto armado \\
\hline \multirow{3}{*}{ BA } & BR-242 & Viaduto $\mathrm{km} \mathrm{229,49}$ & 36,00 & $12^{\circ} 30.591 ' \mathrm{~S}$ & $40^{\circ} 18.406^{\prime} \mathrm{O}$ & 3 & Ponte em laje de concreto armado \\
\hline & BR-101 & Viaduto $\mathrm{km} 188,04$ sobre Ferrovia & 30,90 & $12^{\circ} 29.110^{\prime} \mathrm{S}$ & $38^{\circ} 56.931^{\prime} \mathrm{O}$ & 3 & Viga T ou I de concreto armado \\
\hline & BR-101 & Ponte sobre o Ribeirão Seco & 30,20 & $14^{\circ} 57.042^{\prime} \mathrm{S}$ & $39^{\circ} 18.303^{\prime} \mathrm{O}$ & 3 & Viga T ou I de concreto armado \\
\hline \multirow{3}{*}{$\mathrm{CE}$} & BR-122 & Ponte km 133,24 & 24,60 & $5^{\circ} 10.927 ' s$ & $38^{\circ} 58.086^{\prime} \mathrm{O}$ & 3 & Viga T ou I de concreto armado \\
\hline & BR-020 & Ponte sobre o Riacho Espiroá & 21,95 & $3^{\circ} 50.943$ 'S & $38^{\circ} 46.750^{\prime} \mathrm{O}$ & 2 & Ponte em laje de concreto armado \\
\hline & BR-020 & Ponte sobre o Riacho Salgado & 34,90 & $4^{\circ} 2.759^{\prime} \mathrm{S}$ & $39^{\circ} 0.346^{\prime} \mathrm{O}$ & 3 & Viga T ou I de concreto armado \\
\hline \multirow{3}{*}{ MA } & BR-222 & onte sobre o Igarapé Bate Estaca & 25,50 & $3^{\circ} 40.761 ' \mathrm{~S}$ & $45^{\circ} 15.497^{\prime} \mathrm{O}$ & 2 & Viga T ou I de concreto armado \\
\hline & BR-010 & Ponte sobre o Rio Barra Grande & 40,00 & $5^{\circ} 22.852^{\prime} \mathrm{S}$ & $47^{\circ} 28.590^{\prime} \mathrm{O}$ & 3 & Viga T ou I de concreto armado \\
\hline & BR-010 & Ponte sobre o Rio Sumauma & 25,00 & $5^{\circ} 56.575^{\prime} \mathrm{S}$ & $47^{\circ} 23.025^{\prime} \mathrm{O}$ & 3 & Viga T ou I de concreto armado \\
\hline \multirow{3}{*}{$\mathrm{PA}$} & BR-010 & onte sobre o Igarapé Gurupi-Mirim & 45,00 & $3^{\circ} 43.252^{\prime} \mathrm{S}$ & $47^{\circ} 29.372^{\prime} \mathrm{O}$ & 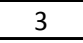 & Viga T ou I de concreto a \\
\hline & BR-306 & Ponte sobre o Rio Jejú & 40,50 & $1^{\circ} 20.294^{\prime} \mathrm{S}$ & $47^{\circ} 32.646^{\prime} \mathrm{O}$ & 3 & Viga T ou I de concreto a \\
\hline & BR-316 & Ponte sobre o Rio Várzea & 30,00 & $1^{\circ} 35.371^{\prime} \mathrm{S}$ & $46^{\circ} 50.424^{\prime} \mathrm{O}$ & 3 & Viga T ou I de concreto armado \\
\hline \multirow{3}{*}{ PB } & BR-104 & onte sobre o Rio Campo Comprido & 30,17 & $6^{\circ} 31.612^{\prime} \mathrm{S}$ & $36^{\circ} 8.598^{\prime} 0$ & 2 & Viga T ou I de concreto armado \\
\hline & BR-104 & Ponte sobre o Rio Meio & 40,40 & $6^{\circ} 36.257^{\prime} \mathrm{S}$ & $36^{\circ} 8.405^{\prime} \mathrm{O}$ & 3 & Viga T ou I de concreto armado \\
\hline & BR-230 & Ponte sobre o Rio Soledade & 30,17 & $7^{\circ} 4.243^{\prime} \mathrm{S}$ & $36^{\circ} 20.868^{\prime} \mathrm{O}$ & 3 & Viga T ou I de concreto armado \\
\hline \multirow{3}{*}{$\mathrm{PE}$} & BR-232 & Ponte sobre o Riacho Urubu & 36,00 & $8^{\circ} 17.007 ' s$ & $37^{\circ} 22.964^{\prime} \mathrm{O}$ & 3 & Viga T ou I de concreto armado \\
\hline & BR-232 & Ponte $\mathrm{km} 318,71$ & 36,40 & $8^{\circ} 7.493^{\prime} S$ & $37^{\circ} 31.856^{\prime} \mathrm{O}$ & 3 & Viga T ou I de concreto armado \\
\hline & BR-232 & Ponte sobre o Riacho Saco da Bola & 39,00 & $8^{\circ} 1.924^{\prime} \mathrm{S}$ & $38^{\circ} 7.785^{\prime} \mathrm{O}$ & 3 & Viga T ou I de concreto armado \\
\hline \multirow{3}{*}{$\mathrm{PI}$} & BR-407 & Ponte sobre o Riacho Lua Nova & 32,45 & $8^{\circ} 24.393^{\prime} \mathrm{S}$ & $41^{\circ} 5.719^{\prime} \mathrm{O}$ & 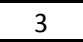 & Viga T ou I de concreto armado \\
\hline & BR-316 & Ponte sobre o Riacho São João & 35,00 & $7^{\circ} 14.774 ' \mathrm{~S}$ & $40^{\circ} 51.519^{\prime} \mathrm{O}$ & 3 & Viga T ou I de concreto armado \\
\hline & BR-343 & Ponte sobre o Riacho do Alegre & 30,00 & $4^{\circ} 55.106 ' \mathrm{~S}$ & $42^{\circ} 15.557^{\prime} \mathrm{O}$ & 2 & Ponte em laje de concreto armado \\
\hline \multirow{3}{*}{ RN } & BR-226 & Ponte km 165,63 & 40,00 & $6^{\circ} 13.723^{\prime} \mathrm{S}$ & $36^{\circ} 26.126^{\prime} \mathrm{O}$ & 4 & Ponte em laje de concreto armado \\
\hline & BR-427 & Ponte sobre o Riacho Boca de Laje & 23,00 & $6^{\circ} 19.882^{\prime} \mathrm{S}$ & $36^{\circ} 33.258^{\prime} \mathrm{O}$ & 3 & Viga T ou I de concreto armado \\
\hline & BR-405 & Ponte sobre o Riacho Grande & 20,00 & $5^{\circ} 11.665 ' S$ & $37^{\circ} 23.132^{\prime} \mathrm{O}$ & 3 & Viga T ou I de concreto armado \\
\hline \multirow{3}{*}{ SE } & BR-101 & Ponte sobre o Rio Riachão (LE) & 18,30 & $10^{\circ} 38.383^{\prime} \mathrm{S}$ & $37^{\circ} 0.729^{\prime} \mathrm{O}$ & 1 & Viga T ou I de concreto armado \\
\hline & BR-101 & 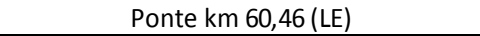 & 18,70 & $10^{\circ} 40.347^{\prime} \mathrm{S}$ & $37^{\circ} 1.733^{\prime} \mathrm{O}$ & 1 & Viga T ou I de concreto armado \\
\hline & BR-101 & Viaduto sobre Ferrovia km 66,93 (LE) & 23,35 & $10^{\circ} 43.099^{\prime} \mathrm{S}$ & $37^{\circ} 3.925^{\prime} \mathrm{O}$ & 3 & Ponte em laje de concreto armado \\
\hline \multirow{3}{*}{ TO } & BR-153 & Ponte sobre o Córrego Feliciano & 34,90 & $10^{\circ} 50.600^{\prime} \mathrm{S}$ & $48^{\circ} 54.277^{\prime} \mathrm{O}$ & 3 & Viga T ou I de concreto armado \\
\hline & BR-153 & Ponte sobre o Rio Pouso do Meio & 30,00 & $11^{\circ} 42.471^{\prime} \mathrm{S}$ & $49^{\circ} 4.459^{\prime} \mathrm{O}$ & 3 & Viga T ou I de concreto armado \\
\hline & BR-153 & Ponte sobre o Rio Pontes & 35,00 & $7^{\circ} 17.057 ' S$ & $48^{\circ} 16.647^{\prime} \mathrm{O}$ & 3 & Viga T ou I de concreto armado \\
\hline
\end{tabular}

A identificação das obras quanto ao trem tipo de dimensionamento e a sua época de construção foi feita a partir do Manual 709 do DNIT (2004). De acordo com o manual, obras que mantiveram suas características originais ou tenham sofrido pequenas alterações podem ser identificadas a partir de suas características geométricas. No caso das OAEs construídas entre 1960 a 1975, é possível notar que as transversinas são ligadas a laje, os guarda rodas são ineficazes, as faixas de segurança possuem comprimento inferior aos acostamentos das vias, a camada de pavimento era de $15 \mathrm{~cm}, \mathrm{o}$ que gerava uma sobrecarga na estrutura, e por fim, a obra não possuia pingadeiras, o que tornava a laje em balanço e as vigas vulneráveis a água das chuvas. A seção tipo característica do período pode ser verificada na figura 2 a seguir.

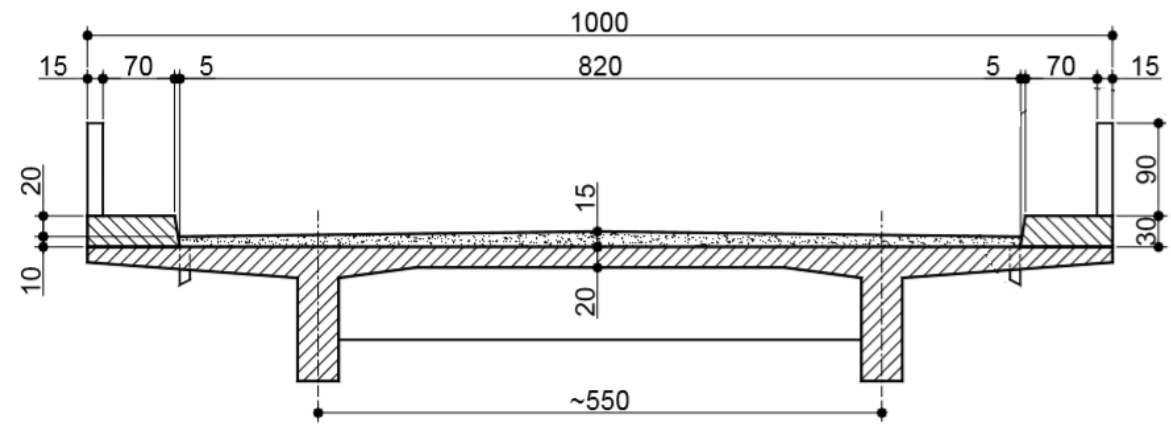

Figura 2: Seção tipo característica de OAEs construídas entre 1960 e 1975 (Manual 709, 2004).

Selecionadas as obras, foi analisado o registro fotográfico das inspeções visuais realizadas de cada uma delas, identificando as deficiências funcionais e patologias. Na sequência, agruparam-se as ocorrências semelhantes e 
elaboraram-se estatísticas, de forma a obter a frequência em que os danos ocorrem e a distribuição dos mesmos em relação aos elementos.

\subsection{Resultados e Discussão}

Primeiramente, obteve-se, de acordo com a figura 3, a distribuição das obras quanto ao seu sistema estrutural. Verificase que a grande maior parte das obras possui o sistema estrutural constituído de vigas de concreto armado, enquanto uma parcela pequena possui apenas a laje em sua superestrutura e outra ainda menor é constituída de viga caixão, ou seja, de seção fechada. Observa-se também que, embora sejam sistemas estruturais muito eficientes, não foram verificadas obras em que se utilizou o concreto protendido ou vigas de perfis metálicos. No caso da protensão, pode-se justificar a ausência do método devido à pequena difusão e disponibilidade do método na época de construção ou do tamanho reduzido dos vãos, enquanto a ausência de pontes mistas é retrata a preferência do mercado de construção brasileiro pelo concreto.

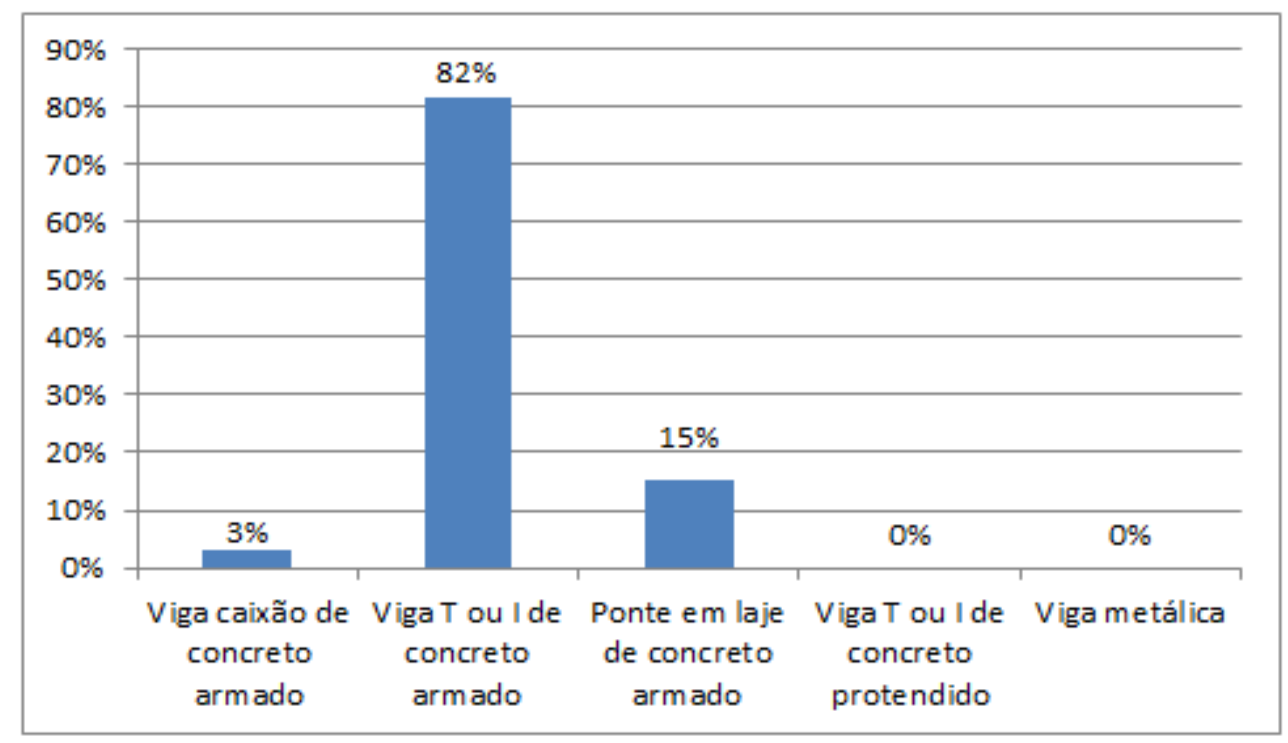

Figura 3: Distribuição quanto ao sistema estrutural das OAEs estudadas.

$\mathrm{Na}$ sequência, foram analisados os aspectos funcionais das obras selecionadas, quantificando a ocorrência por OAE e a proporção que cada deficiência representava dentro do todo. O resultado da ocorrência pode ser visto na figura 4, enquanto as proporções das deficiências funcionais podem ser verificadas na tabela 2 e figura 5 .

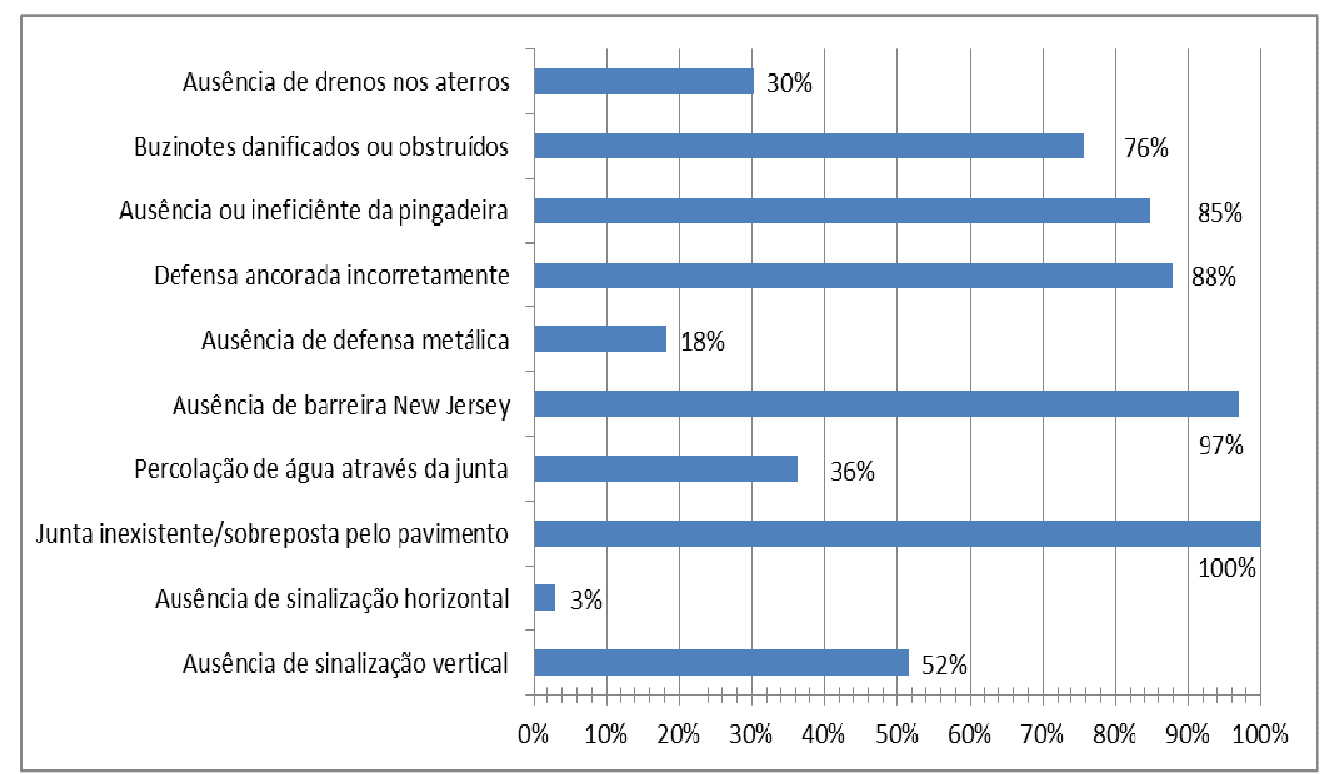

Figura 4: Ocorrência das deficiências funcionais. 
Tabela 2 - Proporção relativa das deficiências funcionais.

\begin{tabular}{|c|c|c|c|}
\hline Deficiência funcional & $\begin{array}{c}\text { Proporção } \\
\text { total }\end{array}$ & Deficiência funcional & $\begin{array}{c}\text { Proporção } \\
\text { total }\end{array}$ \\
\hline Ausência de sinalização vertical & $8,8 \%$ & Ausência de barreira New Jersey & $16,6 \%$ \\
\hline Ausência de sinalização horizontal & $0,5 \%$ & Ausência de defensa metálica & $3,1 \%$ \\
\hline Junta inexistente/sobreposta pelo pavimento & $17,1 \%$ & Defensa ancorada incorretamente & $15,0 \%$ \\
\hline Percolação de água através da junta & $6,2 \%$ & Ausência ou ineficiênte da pingadeira & $14,5 \%$ \\
\hline Ausência de drenos nos aterros & $5,2 \%$ & Buzinotes danificados ou obstruídos & $13,0 \%$ \\
\hline
\end{tabular}

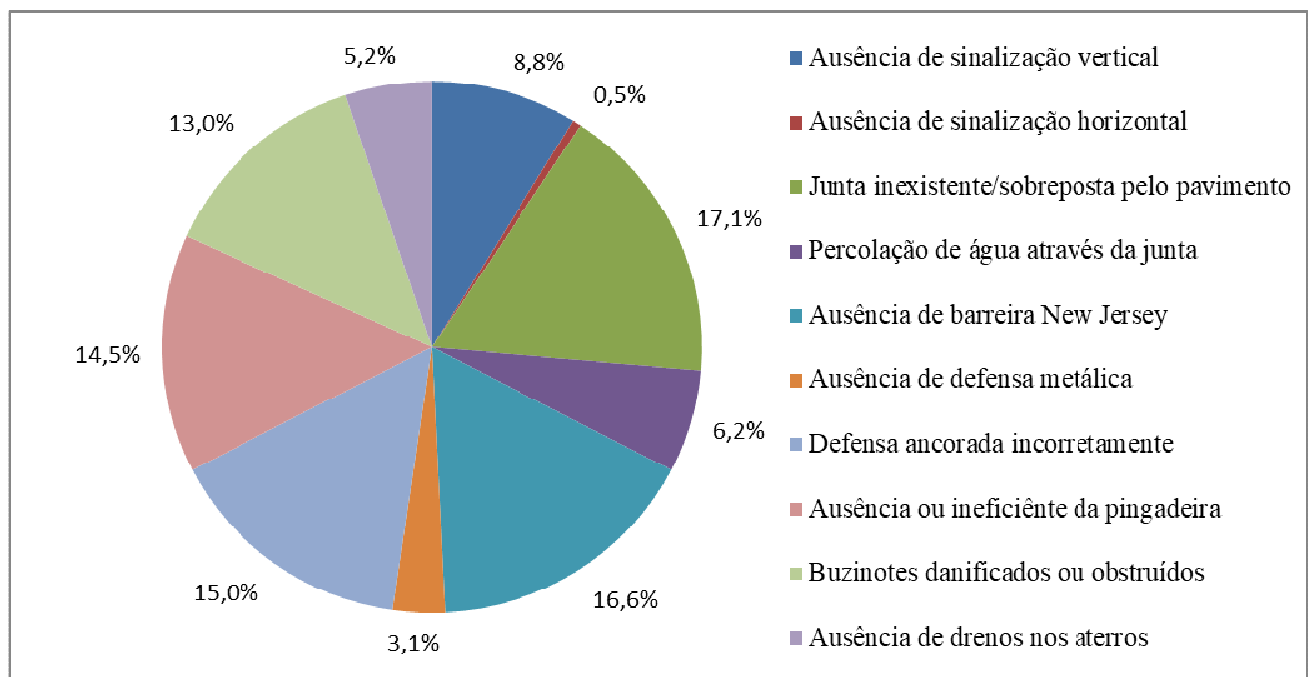

Figura 5: Proporção relativa das deficiências funcionais.

Em relação à sinalização, verifica-se que apenas $3 \%$ das pontes não apresentaram sinalização horizontal. Em contrapartida, pouco mais da metade das obras apresentam algum problema quanto à sinalização vertical. Seguindo a classificação do Manual de Sinalização Rodoviária do DNIT (2010), percebe-se que algumas OAEs não apresentam placas de identificação e indicação de estreitamento de pista, ou seja, de ponte com largura inferior à da via.

A Norma DNIT 092-ES (2006) determina que em caso de manutenção do pavimento, as juntas não devem ser sobrepostas ou obstruídas. Entretanto, observa-se que as juntas sobrepostas pelo recapeamento ou inexistentes representam a maior ocorrência dentre as deficiências, sendo identificadas em todas as obras analisadas, representando quase $15 \%$ do total de deficiências funcionais. Ferreira (2013), afirma que a repavimentação sobre a junta tem como consequência a restrição a liberdade de movimentos, prejudicando o funcionamento dos dispositivos.

Ainda sobre as juntas, $36 \%$ das obras apresentam o elemento danificado, permitindo a percolação de água para a estrutura, o que representa cerca de 5\% das deficiências identificadas. Ramos (2017) atribui a perda de estanqueidade ao rompimento da fita de neoprene e cita como consequências a lixiviação dos elementos do cimento e os ataques por sulfato. Além dos elementos de concreto, a percolação de água pode danificar também os aparelhos de apoio e elementos metálicos.

Ainda de acordo com a Figura 4 e 5, nota-se que existe uma grande deficiência em relação aos dispositivos de segurança das OAEs. 97\% das obras analisadas não possuiam barreiras New Jersey como dispositivos de segurança lateral, mas sim guarda corpos de concreto armado, dispositivo esse destinado a proteção de pedestres. Dessa maneira, os guarda corpos, característicos das obras construídas entre 1960 e 1975, não possuem resistência suficiente diante de choques com veículos. Além disso, $18 \%$ das OAEs não possuiam defensas metálicas nos acessos ou saídas e em 88\%, as defensas metálicas não possuiam ancoragem alguma ou estavam ancoradas aos guarda corpos. Quanto aos guarda corpos de concreto, 4 pontes possuiam trechos em que o dispositivo se encontrava destruído e em outras 12 haviam pontos localizados com desplacamento de concreto ou armaduras expostas e oxidadas. 
Em relação aos aterros de acesso, foi constatada em 30\% das obras a ausência de dispositivos de drenagem nos aterros de acesso. Vitório (2016) destaca a vulnerabilidade dos aterros diante das cheias dos rios, que podem comprometer a estabilidade da estrutura devido ao transporte do solo de aterro.

Já em relação às patologias do aterro, verificou-se que 33\% das OAEs sofriam com erosão e que em outros $9 \%$, a fuga do material havia resultado em buracos na pista, localizados no acesso das obras. Vitório (2015) chama atenção para o risco das erosões, que podem não só afetar os encontros como também causar danos aos sistemas de fundações. O autor ainda indica que a ausência de inspeções rotineiras acentua os prejuízos, uma vez que as patologias só são identificadas diante de sinais visíveis como fissuras, deslocamentos e recalques.

Outro ponto que merece destaque são os dispositivos de drenagem nos tabuleiros. Em $76 \%$ das obras visualizou-se buzinotes danificados ou obstruídos. Uma ocorrência ainda maior foi verificada para pingadeiras ineficientes ou inexistentes, sendo ela de $85 \%$. Somadas, as duas deficiências funcionais são responsáveis por mais de um quarto das deficiências encontradas em todo o estudo.

Silva et al (2017) atribui as manchas de umidade às já citadas deficiências funcionais relacionadas à drenagem, como as juntas não estanques, a ausência de pingadeiras e os buzinotes danificados ou entupidos, chamando atenção para o prejuízo estético gerado, mas também para o favorecimento da oxidação das armaduras. A ocorrência de danos nos principais elementos estruturais de concreto pode ser verificada na tabela 3 .

Tabela 3 - Ocorrência de danos nos principais elementos estruturais de concreto armado.

\begin{tabular}{|c|c|c|c|c|c|c|}
\hline & Laje & Viga & Transversina & Pilar & Viga de Contraventamento & Encontro \\
\hline Manchas de umidade & $100 \%$ & $64 \%$ & $6 \%$ & $33 \%$ & $9 \%$ & $70 \%$ \\
\hline Lixiviação & $73 \%$ & $18 \%$ & $0 \%$ & $6 \%$ & $3 \%$ & $21 \%$ \\
\hline Manchas de Eflorescência ou Carbonatação & $61 \%$ & $9 \%$ & $3 \%$ & $0 \%$ & $0 \%$ & $9 \%$ \\
\hline Fissura ou trinca & $33 \%$ & $3 \%$ & $0 \%$ & $3 \%$ & $0 \%$ & $3 \%$ \\
\hline Concreto desagregado ou Armadura Exposta & $82 \%$ & $48 \%$ & $27 \%$ & $24 \%$ & $15 \%$ & $33 \%$ \\
\hline Mancha ou fragmentação por fogo & $9 \%$ & $9 \%$ & $3 \%$ & $12 \%$ & $3 \%$ & $12 \%$ \\
\hline Deterioração devido a excrementos de morcego & $3 \%$ & $55 \%$ & $52 \%$ & $3 \%$ & $3 \%$ & $0 \%$ \\
\hline
\end{tabular}

De acordo com o resultado exposto na tabela é possível notar que os danos decorrentes da drenagem deficiente são os de maior ocorrência. No caso das manchas de umidade, o dano foi encontrado na laje de todas as OAEs e nas vigas de duas a cada três obras, o que reflete a alta ocorrência de buzinotes e pingadeiras ineficientes. Já o alto número apresentado nos encontros, de 70\%, tem também a participação das juntas não estanques.

Já os danos de lixiviação e eflorescência ou carbonatação, também apresentam grande ocorrência nas lajes embora se apresentem de forma mais tímida nos demais elementos. Mehta e Monteiro (1994), explicam que a lixiviação causa ao concreto uma redução de sua resistência mecânica, além de contribuir com a origem de eflorescências. Para o caso de eflorescências, Morais (2017) indica como consequência a degradação do concreto, enquanto Torres Filho (2017) complementa que em caso de carbonatação, reduz-se a proteção das armaduras, que ficam mais propensas a corrosão diante da presença de oxigênio e umidade.

Observa-se que no caso da deterioração do concreto devido ao acúmulo de excrementos de morcego, ou guano, há uma ocorrência baixa, com exceção das vigas longarinas e transversias. Pereira et al (2019) explica que os excrementos se acumulam entre as longarinas e transversinas, devido a menor exposição a luz solar, inicialmente com coloração mais escura e, a medida que envelhecem, ficam com a coloração mais clara. Steiger (2015) atribui como consequência da degradação biológica a desagregação do concreto, de forma a expor a matriz cimentícia e o aço a agentes externos.

Conforme dito, essas manifestações patológicas contribuem com a degradação do concreto e oxidação do aço, podendo evoluir para a desagregação do concreto e exposição da armadura, sendo esse o segundo dano de maior ocorrência do estudo. Observa-se a maior frequência na laje, principalmente na extremidade da laje em balanço e nas proximidades dos buzinotes danificados.

Mazer (2008) destaca como consequências da corrosão a fissuração e desagregação do concreto, surgimento de manchas avermelhadas, perda de seção e redução de capacidade mecânica do aço. Já Freitas (2017) cita a perda de resistência mecânica dos elementos como consequência da desagregação do concreto, uma vez que ocorre redução geométrica da seção de concreto. 


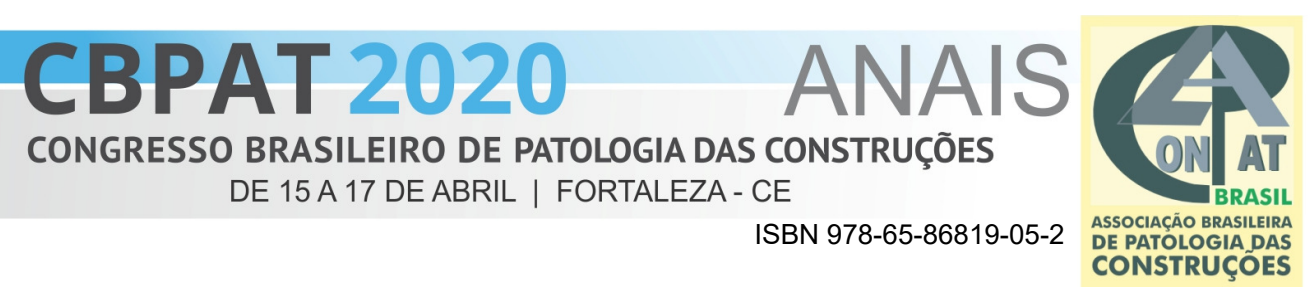

Por fim, com todas as patologias identificadas, levantou-se a frequência com que os elementos apresentam danos, estando o resultado representado pela figura 6. Em seguida, quantificou-se a proporção de danos por elemento a partir do total de ocorrências. Esse quantitativo pode ser verificado na tabela 4 e figura 7.

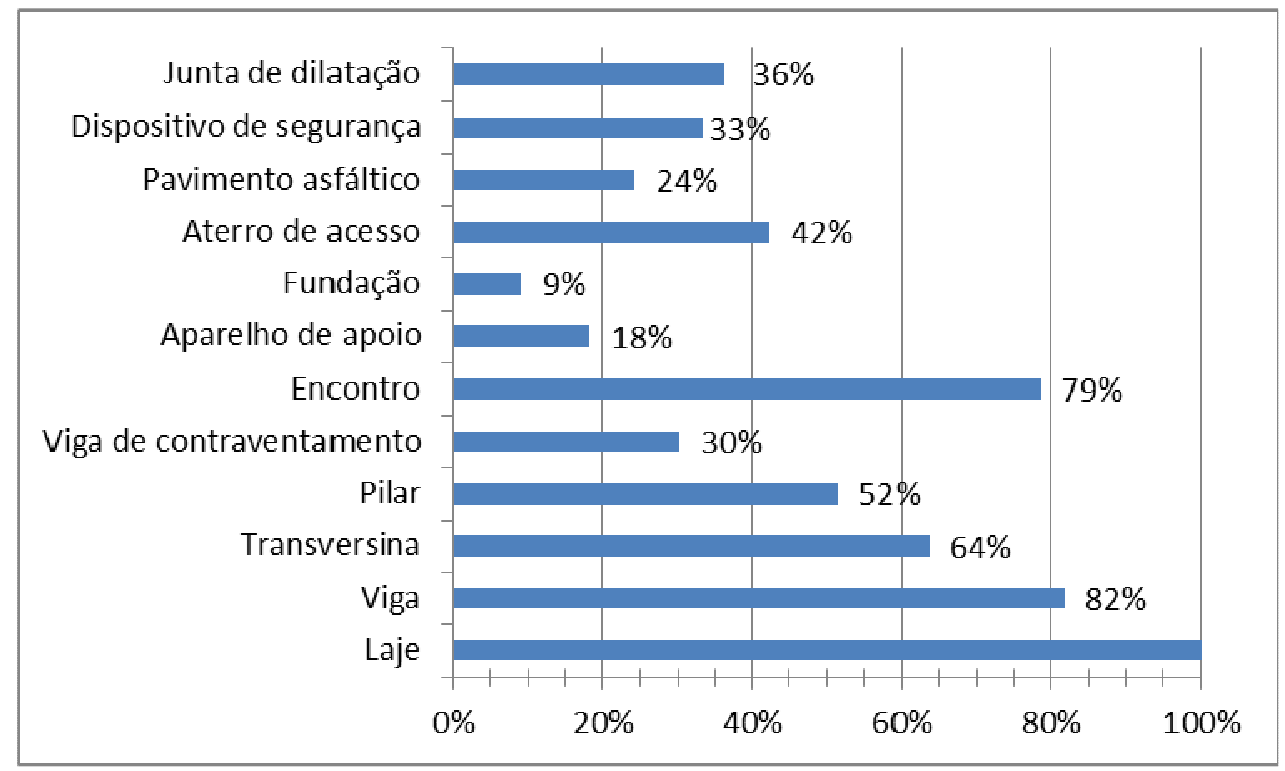

Figura 6: Frequência de danos por Obra de Arte Especial e elemento.

Tabela 4: Proporção de danos por elemento

\begin{tabular}{|c|c|c|c|}
\hline Elemento & Proporção & Elemento & Proporção \\
\hline Laje & $32 \%$ & Aparelho de apoio & $2 \%$ \\
\hline Viga & $18 \%$ & Fundação & $1 \%$ \\
\hline Transversina & $8 \%$ & Aterro de acesso & $4 \%$ \\
\hline Pilar & $7 \%$ & Pavimento asfáltico & $3 \%$ \\
\hline Viga de contraventamento & $3 \%$ & Dispositivo de segurança & $4 \%$ \\
\hline Encontro & $13 \%$ & Junta de dilatação & $4 \%$ \\
\hline
\end{tabular}

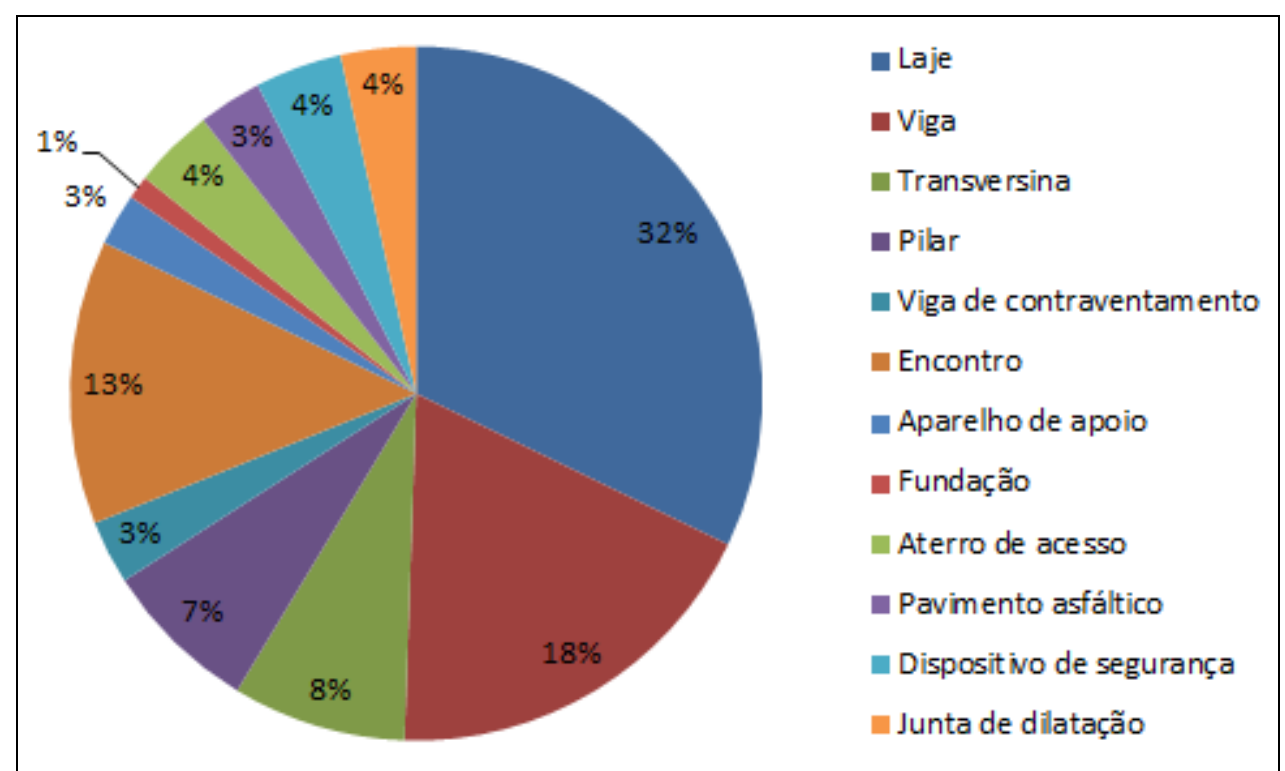

Figura 7: Proporção de danos por elemento.

Dentre os elementos estruturais, nota-se que os elementos que correspondem a menor proporção dos danos são as vigas de contraventamento, elementos de fundação e aparelhos de apoio. As vigas de contraventamento, que já tiveram suas 
manifestações patológicas detalhadas na tabela 2, apresentam 3\% do total de danos encontrados. Já os elementos de fundação representam apenas $1 \%$, mas é importante ressaltar que em grande parte das obras a fundação não está exposta.

Já os aparelhos de apoio representam $2 \%$ dos danos totais, sendo que 5 pontes apresentaram algum aparelho de apoio danificado e outras 4 apresentaram algum aparelho de apoio deslocado de sua posição original. Por outro lado, cabe ressaltar que em 23 das 33 OAEs não foi possível identificar nenhum aparelho de apoio. Mendes et al (2010) alerta que a ausência do dispositivo, assim como o dimensionamento incorreto, pode ter como consequência a fissuração do concreto.

Como já exposto, os elementos que apresentam maior frequência de danos são a laje, vigas e encontros. Isso se dá devido à vulnerabilidade que os mesmos apresentam em relação aos dispositivos de drenagem e à junta de dilatação.

Em relação aos elementos complementares, ou seja, aqueles que não apresentam função estrutural, a proporção se mostra bem aproximada. Os aterros de acesso, dispositivos de segurança e as juntas apresentam, cada uma, 4\% do total dos danos, enquanto o pavimento asfáltico apresenta 3\%. Os danos a cerca do pavimento foram divididos em fissuras ou trincas e buracos na pista, tendo sido verificados em 6 e 5 OAEs, respectivamente.

\section{CONSIDERAÇÕES FINAIS}

O concreto armado é o material estrutural mais utilizado no Brasil. Entretanto, diante da deterioração recente de algumas estruturas, a crença de que o concreto era um material de duração indefinida tem dado espaço à preocupação com a durabilidade do material e consequentemente com o prolongamento da vida útil das construções.

O Manual 709 do DNIT (2004) afirma que o perfil das obras de arte especiais das rodovias brasileiras é bastante heterogêneo. De acordo com o manual, a diversidade se dá devido a constante evolução das normas vigentes, além das intervenções realizadas. Dessa maneira, a determinação de critérios como o trem tipo e a largura da OAE foi de fundamental importância para a seleção de um grupo homogêneo de obras para a pesquisa.

A partir das obras selecionadas foi possível atingir o objetivo da pesquisa, que era de conseguir avaliar e identificar as manifestações patológicas e deficiências funcionais, para traçar quantitativos e estatísticas sobre a ocorrência das mesmas. A partir da avaliação foi possível identificar uma quantidade diversa de danos e problemas que são comumentes encontrados nas OAEs brasileiras.

Rocha et al (2015) já havia afirmado que a situação, tanto em quesitos estruturais quanto funcionais, era pior em obras mais antigas, uma vez que as mesmas eram dimensionadas para um tráfego mais leve e menos intenso que o atual. Nesse sentido, pode-se enfatizar o quadro das deficiências funcionais, uma vez que as mesmas estão associadas às características geométricas da época, a defeitos em dispositivos de segurança ou drenagem obsoletos e a técnicas de engenharia ultrapassadas.

Além disso, foi possível notar algumas correlações entre as manifestações patológicas e as deficiências funcionais. A laje, por exemplo, foi o elemento com a maior quantidade de danos encontrados, seguido pelas vigas longarinas. Nesse caso, coube lembrar que as deficiências relacionadas ao mau funcionamento das pingadeiras e buzinotes também tiveram uma ocorrência grande.

Por fim, diante da grande quantidade de danos encontrados, evidencia-se a importância de inspeções, uma vez que as visitas são importantes ferramentas de avaliação das estruturas. De forma complementar, recomenda-se a elaboração de programas efetivos de manutenção e esforços para que as obras mais antigas tenham suas características adaptadas e compatibilizadas com as normas e instruções mais recentes.

\section{REFERÊNCIAS}

BASTOS, H. C. N.; MIRANDA, M. Z. Principais patologias em estruturas de concreto de pontes e viadutos: Manuseio e manutenção das obras de arte especiais. Revista CONSTUINDO, Belo Horizonte, v. 9, Ed. Esp. de Patologia, p. 93 - 101, Jul - dez., 2017. 
BRASIL. DEPARTAMENTO NACIONAL DE ESTRADAS DE RODAGEM. Diretoria de Planejamento e Pesquisa. Coordenação do Instituto de Pesquisas Rodoviárias. Manual de Inspeção de Pontes Rodoviárias. Rio de Janeiro, 2004. 253p. (IPR. Publicação 709.).

BRASIL. DEPARTAMENTO NACIONAL DE INFRAESTRUTURA DE TRANSPORTES. Diretoria Executiva. Instituto de Pesquisas Rodoviárias. Manual de Sinalização Rodoviária. 3 ed. Rio de Janeiro, 2010. 412p. (IPR. Publicação 743).

DNIT, 2006. NORMA DNIT 092/2006 - ES. Juntas de dilatação - Especificação de Serviço. Instituto de Pesquisas Rodoviárias. Departamento Nacional de Infraestrutura de Transportes. Ministério dos Transportes. Brasil.

FERREIRA, C. M. S. Tipologia, instalação, funcionamento e manutenção de diversos tipos de juntas de dilatação em Obras de Arte. Dissertação - ISEL. Lisboa, 2013.

TORRES FILHO, D. Estado de deterioração das obras de arte do sistema de drenagem das águas do açude grande da cidade de Cajazeiras, Paraíba. XIII Congresso internacional sobre patologia e reabilitação de estruturas, Crato, 2017.

FREITAS, R. R. Estudo das principais patologias em estruturas de concreto armado provenientes apas de concepção, execução e manutenção. Trabalho de conclusão de curso (Graduação em Engenharia Civil). Faculdade Pitágoras de Londrina. Londrina, 2017.

INFOESCOLA. Mapa do Brasil dividido por Estados. Disponível em: <https://www.infoescola.com/geografia/mapado-brasil>. Acesso em: 6 de janeiro de 2020.

MAZER, W. Patologia, recuperação e reforço de estruturas de concreto. Curitiba, 2008.

MEHTA, P. K.; MONTEIRO, P. J. M. Concreto: estrutura propriedades e materiais. São Paulo: PINI, 1994.

MORAIS, R. S. Patologias geradas por erros de execução de estrutura de concreto armado: causas, medidas preventivas e consequências. Trabalho de conclusão de curso. Universidade Regional do Cariri, Juazeiro do Norte, 2017.

MENDES, L. C. et al. (2010). A importância dos aparelhos de apoio na reabilitação de estruturas de ponte. Córdoba, Argentina: CINPAN.

PEREIRA, R. et al. Degradación debido a la acción biológica de excrementos de murciélagos em las obras de arte especiales em las carreteras de Brasil. CONPAT Chiapas 2019. Tuxtla Gutiérrez, México, 2019.

RAMOS, M. O. Estudo da implantação de juntas de dilatação em pontes e viadutos. Trabalho de concluso de curso - ULBRA. Palmas, 2017.

ROCHA, E. A. et al. Pathological manifestations on concrete bridges at Recife's metropolitan area. Journal of Civil Engineering and Architecture 9, 2015.

SILVA, A. C. G.; CAMPOS, G. R.; FILHO, M . L. S. Análise de manifestações patológicas em obras de arte especiais - Estudo de caso e propostas de recuperação. Revista Técnico-Científica do CREA-PR - ISSN 2358-5420 - Ed. Especial - Setembro de 2017.

STEIGER, V. K. Contribuição para o estudo da degradação química da pasta de cimento: Simulação da atividade agressiva do guano de morcegos. Dissertação de Mestrado em Engenharia e Tecnologia de Materiais, Departamento de Engenharia Civil, Pontificia Universidade Católica do Rio Grande do Sul, Porto Alegre, RS, 2015.

VITÓRIO, J. A. P. Fundamentos da erosão nas fundações de pontes e nos aterros de acesso. Curso de especialização em inspeção, manutenção e recuperação de estruturas. Programa de Pós-Graduação em Engenharia. Escola Politécnica de Pernambuco. Recife, 2015. 